$\mathbb{P}$ periodica polytechnica

Chemical Engineering

$56 / 1(2012) 9,19$

doi: $10.3311 /$ pp.ch.2012-1.02

web: http://www.pp.bme.hu/ch

(c) Periodica Polytechnica 2012

RESEARCH ARTICLE

\section{Process considerations of a biorefinery producing value-added products from corn fibre}

\author{
Csaba Fehér / Zsolt Barta / Katalin Réczey
}

Received 2012 -01-18, accepted 2012-05-04

\begin{abstract}
Corn fibre, a co-product of corn wet milling, can be a suitable raw material of a biorefinery producing biofuels and valueadded chemicals. The simulated process is able to produce bioethanol, biomethane and xylitol synergistically, while it also covers its own heat demand. The proposed plant consists of the following process steps: fractionation, enzymatic hydrolysis and ethanol fermentation, distillation and dehydration, anaerobic digestion, biogas upgrading, aerobic waste water treatment, combined heat and power production, xylitol fermentation and recovery. Various scenarios of the biorefinery were investigated and the process configurations were compared in terms of energy efficiency, or mass flows of the products. Incineration of the sludge and production of district heat are found to be effective methods to increase the energy efficiency, on which aerobic sludge yield has a great effect. The solid-liquid separations, which are carried out in filterpress, have a curial role in terms of energy efficiency. Combustion of the solid part of cellulose hydrolysis residue is favourable compared with the anaerobic digestion, except if the dry matter content of the filterpressed solid was set to $30 \%$ instead of $40 \%$. The amounts of the produced xylitol and biomethane are variable, which ensures the ability of market adaptation for the biorefinery.
\end{abstract}

\section{Keywords}

Biorefinery $\cdot$ process simulation $\cdot$ corn fibre $\cdot$ xylitol $\cdot$ biofuels

\section{Acknowledgement}

This work is connected to the scientific program of the "Development of quality-oriented and harmonized $R+D+I$ strategy and functional model at BME” project, supported by the New Hungary Development Plan (Project ID: TÁMOP-4.2.1/B09/1/KMR-2010-0002). The Hungarian National Research Fund (OTKA - K 72710) is also gratefully acknowledged for the financial support.

\section{Csaba Fehér}

Zsolt Barta

Katalin Réczey

Department of Applied Biotechnology and Food Science, BME, Budapest H1111 Szent Gellért tér 4,, Hungary

\section{Introduction}

Bioethanol is expected to be one of the main renewable alternatives replacing fossil fuels in the transport sector [1]. It is very important considering both the danger of running out of fossil fuels in the next decades and environmental problems, like the acceleration of the global warming [2]. Bioethanol used as a transportation fuel can help in reducing carbon dioxide accumulation by allowing the carbon dioxide content of the fossil fuels to remain in storage [3]. Traditional bioethanol production is based on materials rich in sugar or starch. The ethanol production worldwide was 74 billion litres in 2009 [4], and is expected to reach 100 billion litres in 2015 [3]. To be able to meet the future increasing demands, bioethanol also needs to be produced from lignocellulosic feedstocks. However, the economically viable technologies to produce bioethanol from lignocellulosic biomass are still under development all over the world, and no process concept has been demonstrated on an industrial scale yet. The main barrier can be solved by the utilizations of the by-products and wastes of the bioethanol process. Many investigations were carried out in this topic [5]-[8], which led to the idea of producing bioethanol in biorefinery process [9].

The biorefinery concept describes a large highly-integrated complex incorporating individual processes that synergistically convert biomass feedstocks into fuels, electrical power and/or heat, value-added chemicals, and other materials, with zero waste approach [10,11]. Depending on raw materials, technological processes, and products obtained, the following biorefinery platforms can be distinguished: sugar (biochemical), syngas (thermochemical), biogas, or carbon-rich chains platforms [11]. However, they can incorporate other processes from other platforms: e.g. the distillation stillage can be digested anaerobically, or the lignin can be transformed thermochemically in a sugar platform biorefinery. In these cases, the process is called two platform biorefinery. Economic viability of the biorefinery is highly sensitive to raw material cost, operating scale, and energy consumption of the applied process steps. High energy efficiency is of great importance regarding economic feasibility [1]. Increased productivity and efficiency can be achieved through operations that decrease overall energy demand of the biorefin- 
ery process [11]. Many opportunities were discussed with the potential to achieve this goal: $\mathrm{i}$; increasing the dry matter (DM) content during the ethanol fermentation to decrease the energy demand of the distillation step [5] ii; heat integration of the process steps [12] iii; anaerobic digestion of the stillage [13].

In this study, various process configurations of a corn-fibrebased biorefinery having the potential to produce bioethanol, biomethane, xylitol, electricity and heat were investigated. Corn fibre is an abundant and inexpensive by-product of the corn wet milling process, which contributes to about $10 \%$ of the grain dry matter [14]. It is utilized mainly as low-value animal feed, however, as the market of animal feed is limited, the increase of the corn processing may result in market problems for the excess [15]. Many studies were carried out to find the feasible processing of the corn fibre to produce value-added products such as bioethanol, corn fibre gum, xylo-oligosaccharides, corn fibre oil, xylitol, and many other fermentable chemicals or enzymes [14], [16]-[20]. Regarding these publications, corn fibre seems to be promising feedstock for a biorefinery. The configurations of the corn-fibre-based biorefinery modelled in this study were compared in respect of energy efficiency and mass flows of the products.

\section{Materials and methods}

\subsection{Simulation software}

The process was modelled by Aspen Plus flow-sheeting software (Aspen Tech Inc, Cambridge, MA, USA), which is capable to solve mass and energy balances, and to calculate the thermodynamic properties of all the streams involved in the process. The accuracy of the target values adjusted by design specifications is $\pm 0.1 \%$. The physical data for the components were obtained from the built-in database of Aspen Plus, or from databank of National Renewable Energy Laboratory (NREL, Golden, CO) on biomass components [21]. Data not directly available were estimated from data on similar components [22].

\subsection{Raw material}

Corn fibre is assumed to contain $21.3 \%$ starch, $15 \%$ cellulose, $22 \%$ xylan, $10.9 \%$ arabinan, $2.2 \%$ hemicellulosic glucan, $2 \%$ acetate, $14 \%$ protein, $5 \%$ lipids, $3 \%$ lignin and $1 \%$ inorganic compounds related to the dry matter. These data are based on the publication of Kálmán et al. [14]. To close the mass balance, other component is defined, which is not involved in any reaction during the process. The dry matter content of the raw material is assumed to be $40 \%$.

\subsection{Process description}

The proposed biorefinery plant is assumed to process 95000 dry metric ton corn fibre annually. Two base cases of the biorefinery plant - A and B showed in Figs. 1 and 2 , respectively - were modelled and investigated in this study. It is defined as a base requirement for both base cases that the process can supply its own steam requisite. In the base case A, bioethanol, biomethane and in some scenarios also district heat are produced. In the base case B, beyond bioethanol and biomethane, crystalline xylitol is available as a value-added product. In both base cases electricity is produced during steam generation in considerable amount. The part of this electricity not consumed in the plant can be also realized as a product.

\section{Fractionation}

The first major step in the process is the fractionation, which is considered to be one of the most important steps in the biorefinery concept. The fractionation consists of two minor steps. The first step of fractionation is separation of the starch content stuck to the aleuron layer, which is carried out by hot water treatment at $120^{\circ} \mathrm{C}$. The starch content is assumed to be released and solubilized completely [14]. The protein content is solubilized with the conversion factor of 0.236 . Some xylose and arabinose are also released during the hot water treatment (conversion factors of the reactions: xylan to xylose: 0.059 , arabinan to arabinose: 0.055$)$. After hot water treatment the solubilized starch is removed from the solids in filterpress. The second step of fractionation is weak acid treatment by $1 \%$ sulphuric acid at $120^{\circ} \mathrm{C}$ to hydrolyze the hemicellulosic polymers into monomeric sugars. The assumed reactions and the conversion factors are the following: xylan to xylose 0.926, arabinan to arabinose 0.961 , protein to soluble protein 0.455 , glucan to glucose 1 , acetate to acetic acid 0.561 , lignin to soluble lignin 0.767 . The acidhydrolysed hemicellulosic sugars are separated from the solid residue in filterpress only in the base case $B$, while in the base case $\mathrm{A}$, it is recovered with the distillation residue. In both base cases, the WIS (water-insoluble solid) contents before the hot water and the weak acid treatments were set to $30 \%$ and $22 \%$, respectively. The same settings were applied in all filterpress units built in the model, which are the followings. The solid retention of the filterpress was assumed to be 0.99 , and the dry matter content of the solid stream was $40 \%$ (or $30 \%$ in some scenarios). If it is necessary, washing liquid (water) is used to move $90 \%$ of the soluble component into the supernatant. The washing curve is based on a washing model developed for the recovery of lignin from pulp residue [22,23]. The reactions and the conversion factors used in the model are based on the publication of Kálmán et al. [14]. Although the results reported in this article are based on fractionation experiments carried out at $10 \%$ WIS content, the conversion factors built in the model, where the treatments are performed at higher WIS content, were assumed to be the same.

\section{Enzymatic hydrolysis and ethanol fermentation}

The starch fraction is liquefied at $90^{\circ} \mathrm{C}$ by $\alpha$-amylase and then saccharified by glucoamylase. The total amount of starch is assumed to be converted into glucose. The enzyme loadings of $\alpha$-amylase and glucoamylase are 0.025 and $0.055 \mathrm{~g}$ enzyme preparation/g starch, respectively [24]. The cellulose fraction containing $10 \%$ WIS is directed to cellulose hydrolysis, which 


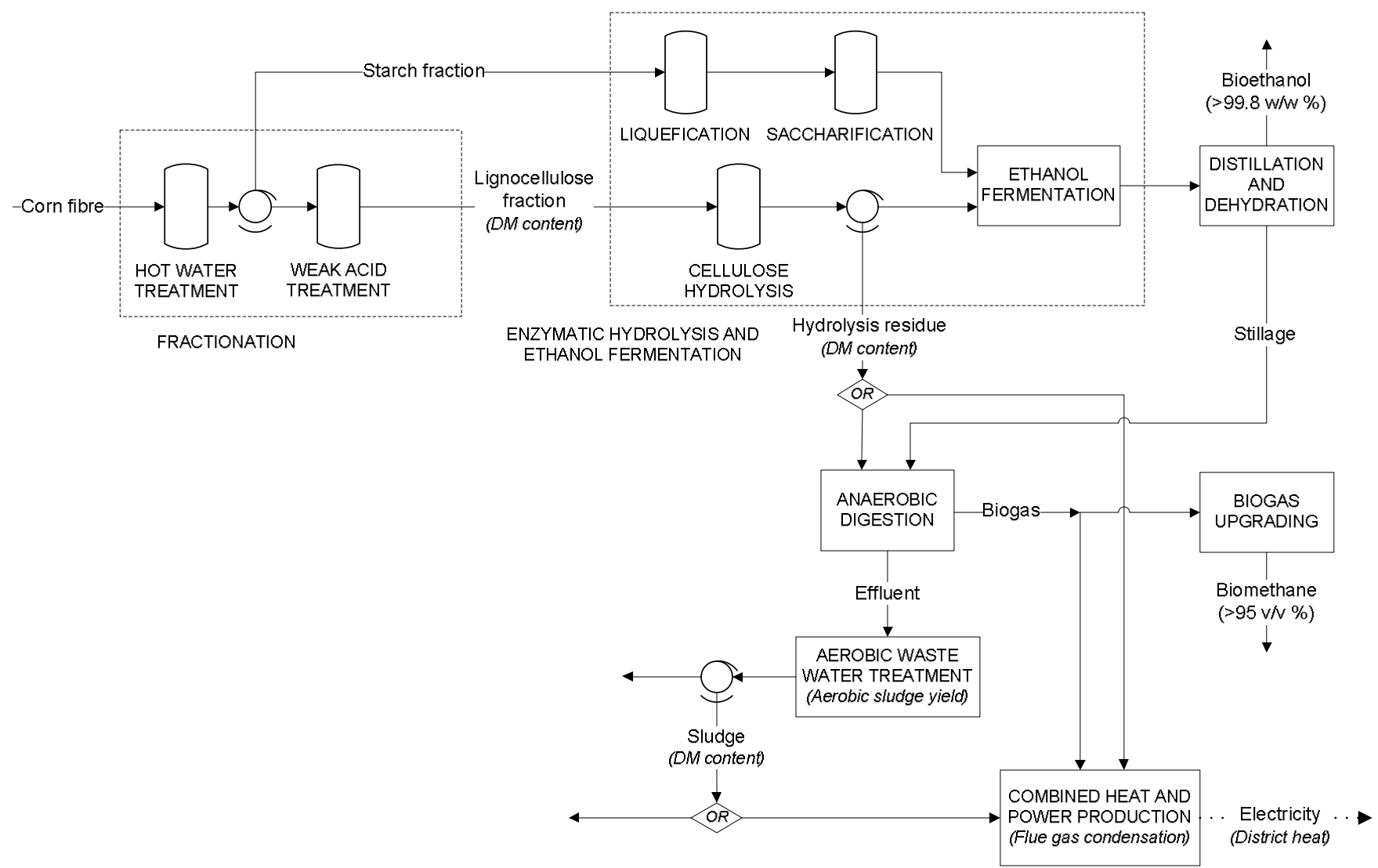

Fig. 1. Overall process scheme for the base case A of the proposed biorefinery plant. Continuous lines: material streams. Dotted line: energy stream. Texts in italics refer to the parameters, which are changing in the different scenarios. DM: dry matter.

\section{Distillation and dehydration}

Distillation and molecular sieve adsorption are used to produce pure $(>99.8 \%)$ ethanol. The distillation step consists of two parallelly operating stripper columns (25 trays) to separate the ethanol from the fermented broth, and a rectification column (35 trays) to concentrate the ethanol to $94 \%$. The columns operate at different pressures to be thermally coupled in order to reduce the energy demand. The feed is preheated in two steps, first by process streams and then by primary steam, before being divided between the two strippers. Overhead vapour from the first stripper ( 3 bar) is used as heating medium in the reboiler of the second stripper before being fed to the rectifier. The overhead vapour from the second stripper ( $1.25 \mathrm{bar}$ ) is used as heating medium in the reboiler of the rectifier, together with some primary steam, if it is necessary. The ethanol recovery is set to $99.5 \%$ in the three columns. Considering the presence of solids such as lignin and yeast in the feed stream, the strippers operate with a modest Murphree efficiency (50\%). The rectifier operates without solids, so the Murphree efficiency was set to a higher value $(75 \%)$. The remaining water in the overhead vapour ( 0.35 bar) leaving the rectifier is removed in the dehydration columns, which are then regenerated with pure ethanol stream. The regenerate is returned to the rectifier [26]. 


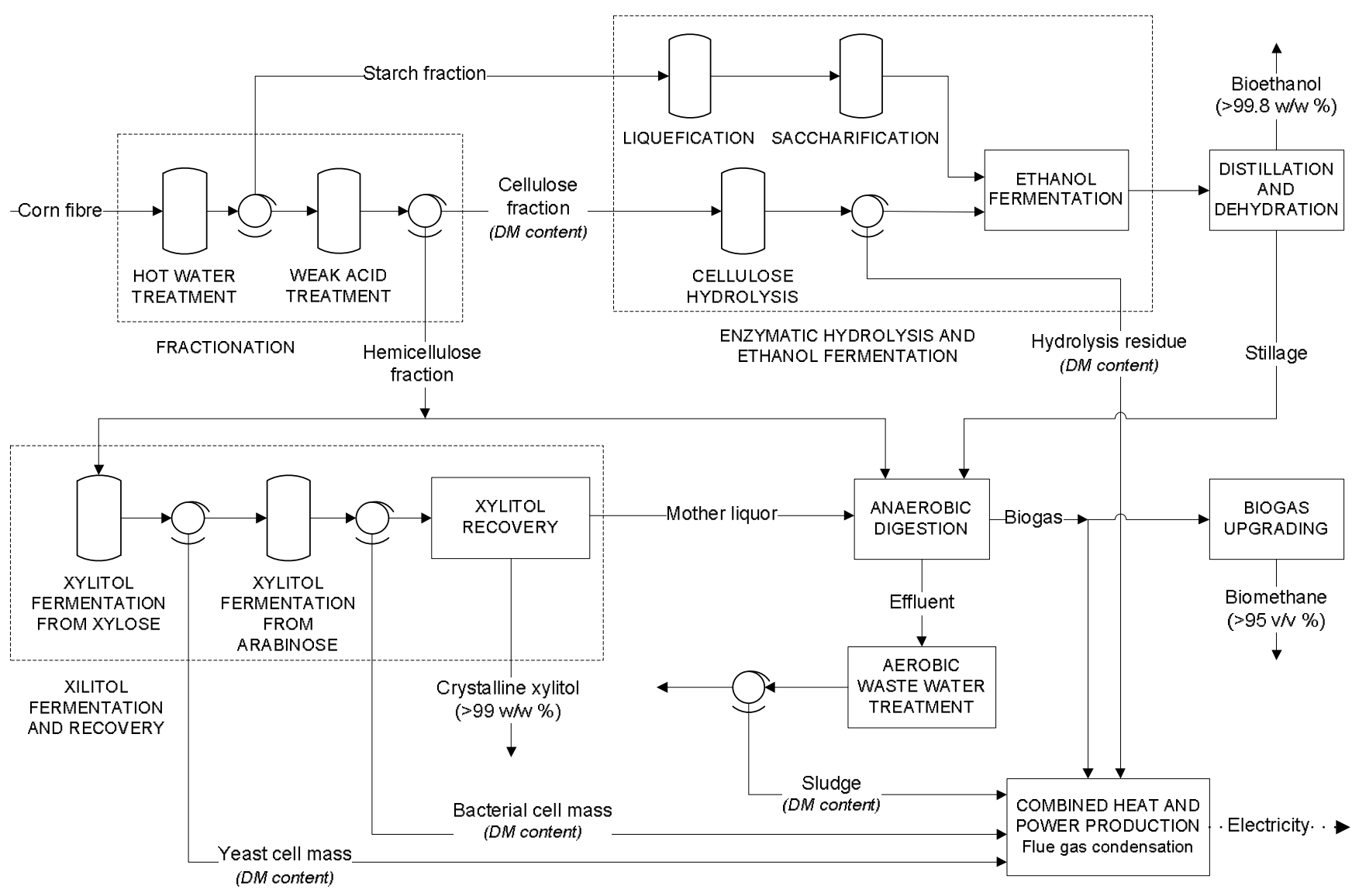

Fig. 2. Overall process scheme for the base case B of the proposed biorefinery plant. Continuous lines: material streams. Dotted line: energy stream. Texts

\section{Anaerobic digestion}

The feed streams of the anaerobic digestion (AD) are the stillage derived from the distillation and in some scenarios the separated hydrolysis residue. In the base case B, one more stream is directed to the $\mathrm{AD}$, referred to as mother liquor, which is derived from the xylitol recovery. Anaerobic digestion is performed under mesophilic conditions, hence the inlet flows are cooled down to $37^{\circ} \mathrm{C}$ before being fed to the digester. The assumed degradation factors are $90 \%$ for soluble sugars, organic acids, sugar alcohols, ethanol, enzymes, yeast and water-soluble protein; $50 \%$ for polysaccharides, water-insoluble proteins, lipids and water-soluble lignin; $0 \%$ for water-insoluble lignin. The yields of the methane and the anaerobic sludge are assumed to be $0.35 \mathrm{Nm}^{3} / \mathrm{kg}$ COD (chemical oxygen demand) removed and $0.03 \mathrm{~kg}$ sludge DM/ $\mathrm{kg}$ COD fed, respectively. All organic components were involved in the COD calculations, except for the water-insoluble lignin, as it was considered to be inert in respect of biogas and sludge production. The biogas is assumed to consist of approximately $50 \%$ methane, $46 \%$ carbon dioxide and $4 \%$ water [13].

\section{Biogas upgrading}

If biogas is expected as a marketable product like fuel for the transport sector, or support for the natural gas grid, it is needed to purify the methane. The removal of carbon dioxide and water is performed in the gas upgrading step, which is based on amine in italics refer to the parameters, which are changing in the different scenarios. DM: dry matter.

absorption-desorption, for which data were obtained from the literature [27]. The upgrading step consists of an absorption column to react the carbon dioxide with amine solution, and a desorption column to regenerate the carbon dioxide rich liquid leaving the absorption column. The raw biogas containing large amount of carbon dioxide is introduced at the bottom of the absorption column, and travels counter-current to the amine solution introduced at the top of the column. The absorption column is operated at high pressure ( 8 bar) and the product stream, which is taken away from the top of the tower, consists of more than $95 \mathrm{v} / \mathrm{v} \%$ methane. Hence, it can be called as biomethane. The carbon dioxide rich amine solution is sent to the top of the desorption tower, which is equipped with a reboiler, and operates at atmospheric pressure. The carbon dioxide rich amine solution from the adsorption tower is pre-heated with the regenerated amine solution. Losses of amine and water are made up, and the lean amine solution is pumped back to the absorption tower. The amine used is diethanolamine (DEA). The DEA load is $2.5 \mathrm{~mol}$ amine/mole carbon dioxide, and the DEA concentration is $15 \mathrm{w} / \mathrm{w} \%$. The boilup ratio in the reboiler was set to achieve $90 \%$ regeneration of the amine solution [28].

\section{Aerobic waste water treatment}

The whole effluent of the anaerobic digestion is driven to the aerobic waste water treatment to remove the remaining organic materials. The organic material is assumed to be removed en- 
tirely, so the degradation factors of all organic compounds are unity. The aerobic sludge is presumed to form at a yield of 0.5 $\mathrm{kg}$ sludge DM/kg COD [29] (or $0.3 \mathrm{~kg}$ sludge DM/kg COD in some scenarios). The sludge is separated from the liquid fraction in filterpress. The liquid fraction can be treated e.g. in ozone treatment to produce clean water. After the aerobic treatment, however, no more water cleaning steps were considered in this study.

\section{Combined heat and power production}

Superheated steam $\left(91\right.$ bar, $\left.470^{\circ} \mathrm{C}\right)$ is generated in a steam boiler by burning one part of the raw biogas and in some scenarios also the hydrolysis residue, the sludge and the separated cell mass from the xylitol production. The heat losses in the steam boiler are assumed to be $1 \%$. The generated steam is allowed to expand to 4 bar through a high-pressure turbine to produce electricity. The isentropic and the mechanical efficiency of the turbine are presumed to be $90 \%$ and $97 \%$, respectively. The amount of the biogas incinerated in the burner is set to produce enough saturated steam of 4 bar, which can satisfy the process heat demand. The return liquid from the heating system of the process, which is $144^{\circ} \mathrm{C}$ and 4 bar, is used as the feed water for the superheated steam generation. The flue gases leaving the boiler are used to preheat the feed water to $220^{\circ} \mathrm{C}$ and then the air used for combustion. The temperature of the flue gases after the air heater is fixed at $150^{\circ} \mathrm{C}$. At this temperature, the leaving flue gases consists of considerable amount of steam as the solid feeds of the burner have relatively low DM content $(40 \%$ or $30 \%$ ). Some of this latent heat can be utilized in the flue gas condenser, in which the temperature of the flue gases is reduced to $50^{\circ} \mathrm{C}$. The recovered heat is consumed during the production of district heat in some scenarios of the base case A, and in the evaporation of the fermented broth derived form the xylitol production in the base case $\mathrm{B}$. The temperature of the return water from the district-heating system is raised from $45^{\circ} \mathrm{C}$ to $90^{\circ} \mathrm{C}$ by passing the stream through the flue gas condenser and by the help of condensating some of the 4 bar steam withdrawn from the high-pressure turbine.

In one configuration the whole raw biogas is combusted in base case $\mathrm{B}$, hence some steam is produced in excess. In this scenario a low-pressure turbine is built in the combined heat and power production (CHP) step to utilize the excess steam by producing more electricity. The pressure of steam after the low-pressure turbine is set to 1 bar. The isentropic and the mechanical efficiency of the low-pressure turbine are presumed to $85 \%$ and $97 \%$, respectively [12].

\section{Xylitol fermentation and recovery}

The xylitol fermentation and recovery steps are implemented only in the base case B, in which the hydrolysed hemicellulosic sugars are separated from the solid fraction, before the ethanol fermentation. The hemicellulose fraction is utilized to produce xylitol from xylose and arabinose in two fermentation steps, op- erating sequential. In the first step the whole xylose content is consumed by a Candida yeast strain to produce xylitol and cell mass. The conversion factor of the xylose to xylitol reaction was set to 0.671 based on literature data [30]. The remaining xylose and the glucose fed are utilized by the yeast to form cell mass with a yield of $0.5 \mathrm{~g} \mathrm{DM} / \mathrm{g}$ sugar. After the first fermentation the cell mass is separated from the broth in filterpress to prevent the xylitol consumption by the Candida yeast, which may occur after the depletion of the other carbon sources [30]. In the second fermentation step, the xylitol formation from arabinose is carried out by a genetically engineered Escherichia coli strain, with the conversion factor of 0.709 [31]. This strain is assumed to use glycerol in order to maintain the redox balance in the cells, and to form cell mass. The amount of the added glycerol is half of the arabinose input, and is consumed entirely [31]. The cell yield is assumed to be $0.4 \mathrm{~g} \mathrm{DM} / \mathrm{g}$ glycerol. A by-product reaction takes into account that $4.7 \%$ of the arabinose is converted to ribitol [31]. Rest of the arabinose remains in the fermentation broth. The genetically modified Escherichia coli cell mass is separated from the xylitol-rich broth in filterpress. The downstream steps are clarification with activated charcoal, evaporation and crystallization [32] (Figure 3). The xylitol-rich broth is treated with charcoal at a concentration of $15 \mathrm{~g} / \mathrm{L}$ to remove the impurities, which can color the xylitol crystals. During this step, $69 \%$ of the protein is removed, however, $5 \%$ of the sugars and sugar alcohols are also adsorbed to the charcoal surface. Separation of the solid and liquid fractions is performed in filterpress. To concentrate the liquid fraction until a xylitol concentration of $637 \mathrm{~g} / \mathrm{L}$, before the crystallization, vacuum evaporation $(0.1 \mathrm{bar})$ is used. Hence, the side reactions and the thermal decomposition can be avoided. In the model xylitol is crystallized from the purified and concentrated broth in one step at $8^{\circ} \mathrm{C}$. However, in the reality it is carried out in two steps (nucleation and growth of crystals) at different temperature $\left(-20^{\circ} \mathrm{C}\right.$ and $8^{\circ} \mathrm{C}$, respectively) [32]. The crystallization yield is set to $47 \%$, which can be achieved with recirculation of the mother liquor at least four times [32]. It is assumed that the xylitol losses during separation the crystals from the mother liquor are negligible. The purity of the recovered crystals is assumed to be more than $99 \%$.

\subsection{Comparison of the scenarios}

The scenarios in the base case A were compared in terms of energy efficiency, which is defined as the energy output divided by the energy input, based on the higher heating values. During energy efficiency calculation raw material was considered as input, while the products (bioethanol, biomethane, district heat) and the electricity produced in the CHP were considered as output. In the base case $\mathrm{B}$, the comparison of the scenarios is based on the mass flows of the products instead of their energy efficiencies, since xylitol is produced to be used as a food component and not as energy carrier. Within the two base cases 14 scenarios were investigated, which differed in process configuration and values of parameters. The configurations are shown 


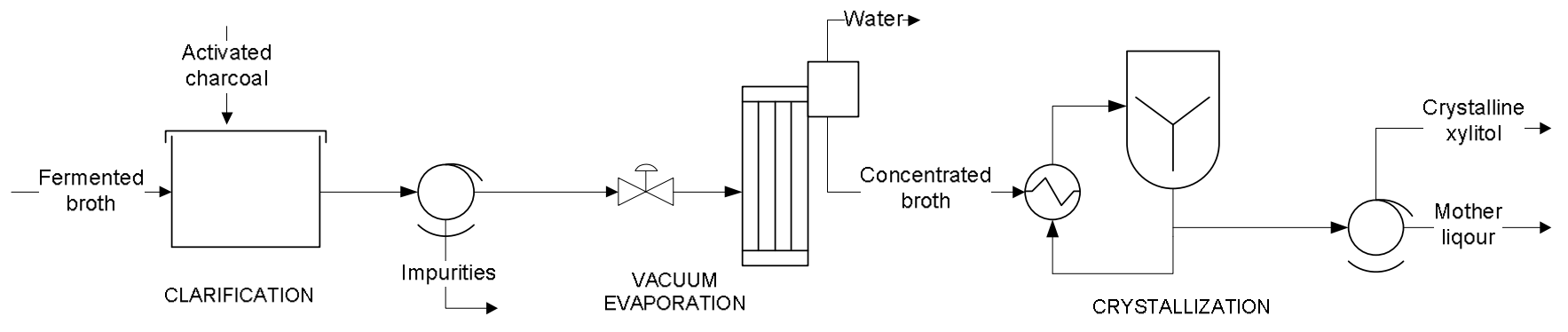

Fig. 3. Process steps of xylitol recovery

in Figs. 1 and 2 and the details of the scenarios are presented in Table1

\section{Results and discussion}

\subsection{Base case A}

Before the study of the configurations detailed above, a preinvestigation was carried out. In accordance with the laboratory experiments of Kálmán et al. [14] the WIS content in the steps of fractionation were set to $10 \%$, which resulted in 5\% WIS concentration in the following cellulose hydrolysis. In some cases of the pre-investigation, the biorefinery process was not able to produce enough steam to satisfy its own heat demand, although it had been defined as a base requirement. However, if the sludge, the hydrolysis residue and the whole amount of biogas were incinerated, and if the feed stream of the plant was preheated in the flue gas condenser, the appropriate amount of steam could be generated. Nevertheless, the energy efficiency was only $38 \%$, which is considered not to be satisfactory on an industrial scale. This low energy efficiency was due to the low ethanol concentration in the fermented broth, which considerably raised the energy demand of the distillation (data not shown). To achieve higher energy efficiencies, higher WIS concentrations were set, namely $30 \%$ and $22 \%$ in the hot water and weak acid treatments, respectively. These values resulted in 10\% WIS content in the cellulose hydrolysis step.

There are two options for the utilization of the hydrolysis residue: subjecting it to the $\mathrm{AD}$ to produce biogas, or incinerating it in the CHP to generate steam and electricity. Fig. 4 clearly shows that the scenarios, in which the hydrolysis residue is incinerated (A1, A2, A3, A7), have higher energy efficiencies, than the corresponding scenarios (A4, A5, A6, A8, respectively), in which the hydrolysis residue is digested anaerobically, while the other settings are equal. There is only one exception, namely the two scenarios in which the dry matter of the filterpressed solid streams is set to $30 \%$ (cases A9 and A10). It is difficult to explain this exception, because the DM content of the filterpressed solid streams has effect on many process steps. The favourable influence of incinerating the hydrolysis residue can be explained as follows. The hydrolysis residue contains mainly water-insoluble lignin, which can not be utilized in the $\mathrm{AD}$, water-soluble lignin, proteins and lipids, which have the conversion factors of 0.5 during the biogas production. Hence, one part of the hydrolysis residue is remained undigested after the $\mathrm{AD}$, and is eliminated in the aerobic waste water treatment step, where aerobic sludge is produced with a yield of $0.5 \mathrm{~kg}$ $\mathrm{DM} / \mathrm{kg}$ COD, however, part of the organic material is degraded to carbon dioxide and water. Thus, the energy from the incineration of the hydrolysis residue is more, than the energy from the incineration of the biogas and sludge, which are produced from the hydrolysis residue (data not shown). When the hydrolysis residue is subjected to AD instead of incineration, more raw biogas is produced (Table 2). Nevertheless, more raw biogas is needed in the burner to cover the process energy demand (Table 2), which results in decreased biomethane production (Table 2) in the cases of A4, A5, A6, A8 compared with their corresponding scenarios (A1, A2, A3, A7, respectively).

The differences between the cases $\mathrm{A} 1$ and $\mathrm{A} 2$, and between the cases A4 and A5 show the significant effect of sludge incineration (Fig. 4). The sludge replaces some biogas required by the burner, thus more biomethane can appear as product, resulting in higher energy efficiency. Processing of the sludge increases the energy efficiency to a larger extent, when the hydrolysis residue is subjected to anaerobic digestion, that is the difference between A4 and A5 is greater than that between A1 and A2. The reason is that during the aerobic treatment more sludge is produced from the lignin, proteins and lipids, remained from the hydrolysis residue after $\mathrm{AD}$, in scenario $\mathrm{A} 5$, compared to case $\mathrm{A} 2$, in which the hydrolysis residue is incinerated.

If streams like the hydrolysis residue and the sludge, which contain water in considerable concentration, are subjected to the burner, large amount of energy is leaving with the flue gas in the form of steam. In the scenario A1, this waste energy is more than in the case A4 (Table 2), which is due to the water content of the incinerated hydrolysis residue. However, comparing case A2 to case A5, the energy leaving with the flue gas is smaller in case A5. In scenario A5 more sludge is produced, which results in more incoming water to the burner.

The energy leaving with the flue gas can be utilized in a flue gas condenser, which is implemented in the configurations of A3 and A6 (Table 2). However, to produce district heat it is also necessary to consume some primary steam. To achieve this goal, more biogas have to be incinerated compared the cases without flue gas condensation. At the same time, the increased steam production results in more electricity (Table 2). The highest en- 
Tab. 1. Process configurations and parameters set in the investigated scenarios.

\begin{tabular}{|c|c|c|c|c|c|c|c|c|}
\hline Scenarios & $\begin{array}{l}\text { Processing of the } \\
\text { hydrolysis residue }\end{array}$ & \multicolumn{2}{|c|}{$\begin{array}{l}\text { Aerobic sludge } \\
\text { yield) }\end{array}$} & $\begin{array}{l}\text { DM content of } \\
\text { the filter } \\
\text { pressed solid } \\
\text { streams (\%) }\end{array}$ & $\begin{array}{l}\text { Processing of } \\
\text { the sludge }\end{array}$ & $\begin{array}{l}\text { Utilizing the } \\
\text { heat of } \\
\text { flue gas con- } \\
\text { sideration }\end{array}$ & \multicolumn{2}{|c|}{ Part of the hemicellulose fraction to } \\
\hline A1 & $\mathrm{CHP}$ & 0.5 & & 40 & - & - & & - \\
\hline A3 & $\mathrm{CHP}$ & 0.5 & & 40 & $\mathrm{CHP}$ & District heating & & - \\
\hline A4 & $A D$ & 0.5 & & 40 & - & - & & - \\
\hline A5 & AD & 0.5 & & 40 & $\mathrm{CHP}$ & - & & - \\
\hline A6 & $A D$ & 0.5 & & 40 & $\mathrm{CHP}$ & District heating & & - \\
\hline A7 & $\mathrm{CHP}$ & 0.3 & & 40 & $\mathrm{CHP}$ & - & & - \\
\hline A8 & AD & 0.3 & & 40 & $\mathrm{CHP}$ & - & & - \\
\hline A10 & $A D$ & 0.5 & & 30 & $\mathrm{CHP}$ & - & & - \\
\hline B1 & $\mathrm{CHP}$ & 0.5 & & 40 & $\mathrm{CHP}$ & Evaporation & 0.8 & 0.2 \\
\hline B2 & $\mathrm{CHP}$ & 0.5 & & 40 & $\mathrm{CHP}$ & Evaporation & 0.8 & 0.2 \\
\hline B3 & $\mathrm{CHP}$ & 0.5 & & 40 & $\mathrm{CHP}$ & Evaporation & 0.5 & 0.5 \\
\hline B4 & $\mathrm{CHP}$ & 0.5 & & 40 & $\mathrm{CHP}$ & Evaporation & 0.3 & 0.7 \\
\hline
\end{tabular}

Base cases $A$ and $B$ are shown in Figs. 1 and 2 respectively. CHP: combined heat and power, AD: anaerobic digestion,

DM: dry matter, COD: chemical oxygen demand.

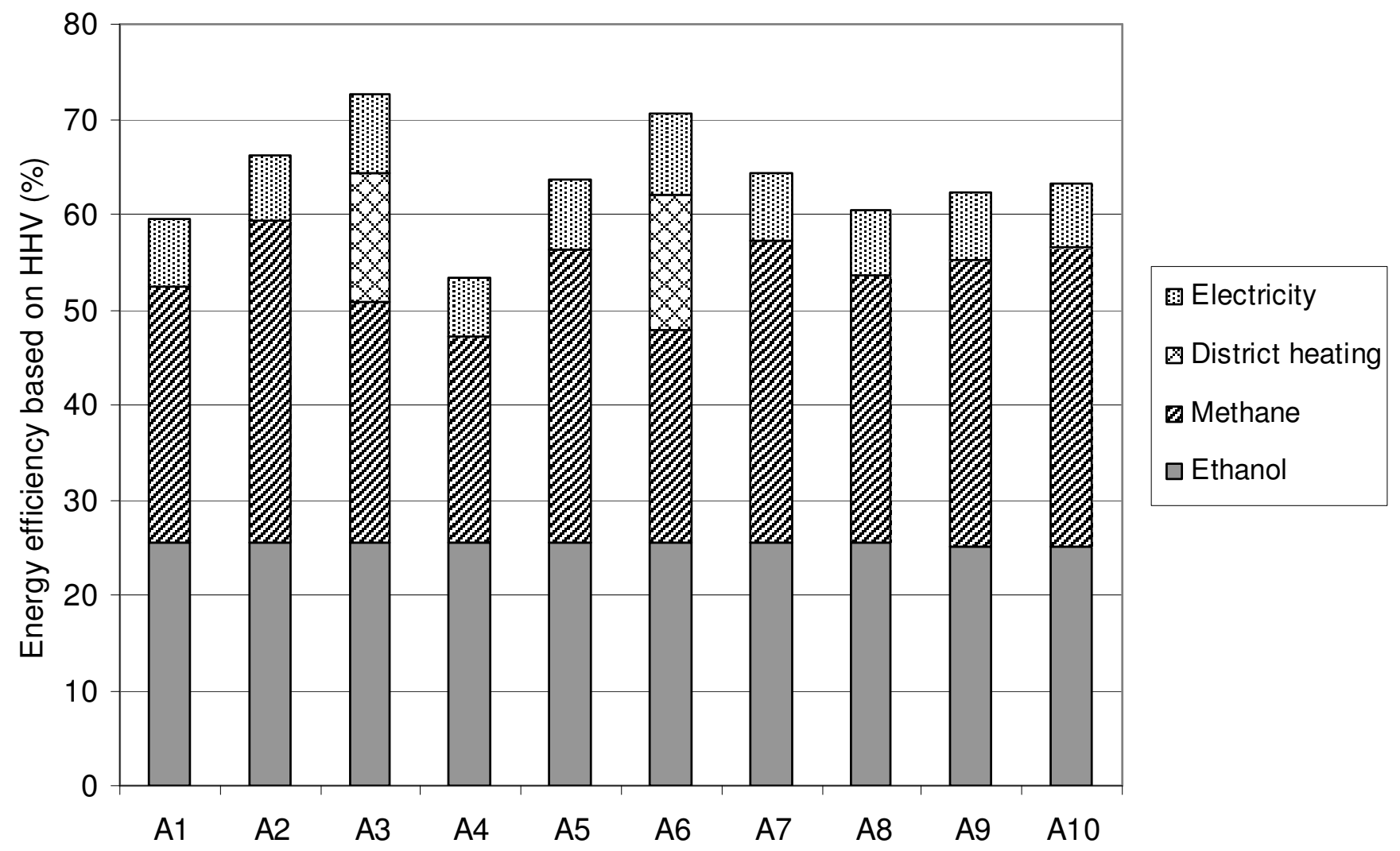

Fig. 4. Energy efficiencies of the investigated scenarios of base case A. Summary of the scenarios is given in Table 1 HHV: higher heating value.

ergy efficiency is achieved in the scenario A3, which contains flue gas condensation and incineration of both the hydrolysis residue and the sludge.

In case A2 less sludge is burnt compared with case A5, and in case A3 less energy can be recovered in the flue gas condenser in contrast with case A6 (Table 2). Hence, the positive effect of sludge utilization and flue gas condensation on the energy efficiency is greater in the cases, where the hydrolysis residue is digested anaerobically.

The yield of the aerobic sludge depends on the composition of the feed and some other environmental parameters [33]. There have not been any experimental data for the aerobic treatment of this kind of material in the literature, thus the assumption of the aerobic sludge yield is very uncertain. Therefore the effect of 
Tab. 2. Process details of the scenarios studied in base case A.

\begin{tabular}{|c|c|c|c|c|c|c|c|c|c|c|c|}
\hline & & \multicolumn{7}{|c|}{ Energy flows of the CHP block (MW) } & \multicolumn{3}{|c|}{ Energy flows of the products (MW) } \\
\hline & & \multicolumn{3}{|c|}{$\ln$} & \multicolumn{4}{|c|}{ Out } & & & \\
\hline Scenarios & 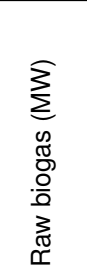 & 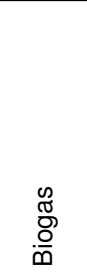 & 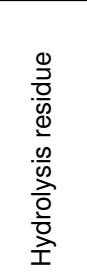 & $\frac{\stackrel{D}{\frac{O}{0}}}{\frac{D}{\text { 心 }}}$ & 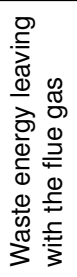 & 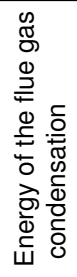 & 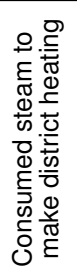 & 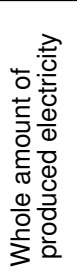 & 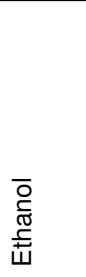 & 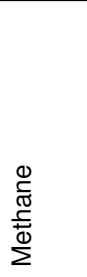 & 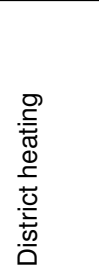 \\
\hline $\mathrm{A} 1$ & 24.67 & 9.19 & 14.26 & - & 2.98 & - & - & 4.00 & 14.64 & 15.43 & - \\
\hline $\mathrm{A} 2$ & 24.68 & 5.24 & 14.26 & 4.68 & 3.66 & - & - & 4.00 & 14.64 & 19.38 & - \\
\hline A3 & 24.70 & 10.10 & 14.26 & 4.68 & - & 4.05 & 3.90 & 4.71 & 14.64 & 14.55 & 7.69 \\
\hline A4 & 32.49 & 20.11 & 14.26 & - & 1.61 & - & - & 3.66 & 14.64 & 12.34 & - \\
\hline A5 & 32.45 & 14.71 & 14.26 & 10.50 & 3.92 & - & - & 4.16 & 14.64 & 17.68 & - \\
\hline A6 & 32.47 & 19.65 & 14.26 & 10.50 & - & 4.32 & 3.90 & 4.87 & 14.64 & 12.78 & 8.23 \\
\hline A7 & 24.68 & 6.41 & 14.26 & 3.37 & 3.47 & - & - & 4.01 & 14.64 & 18.21 & - \\
\hline A8 & 32.47 & 16.31 & 14.26 & 7.12 & 3.34 & - & - & 3.93 & 14.64 & 16.11 & - \\
\hline A9 & 24.44 & 7.07 & 14.81 & 4.63 & 5.31 & - & - & 4.12 & 14.33 & 17.32 & - \\
\hline A10 & 32.72 & 14.64 & 14.81 & 10.53 & 5.21 & - & - & 3.89 & 14.33 & 18.02 & - \\
\hline
\end{tabular}

Summary of the scenarios is given in Table $1 \mathrm{CHP}$ : combined heat and power. Waste energy leaving with the flue gas and energy of the flue gas condensation were determined by cooling the flue gas from $150^{\circ} \mathrm{C}$ to $50^{\circ} \mathrm{C}$. Energy content of the raw material is $57.33 \mathrm{MW}$.

this parameter was investigated in two level. Changing the aerobic sludge yield from 0.5 (cases A2 and A5) to $0.3 \mathrm{~kg} \mathrm{DM} / \mathrm{kg}$ COD (cases A7 and A8), the energy efficiency decreases significantly. At the lower aerobic sludge yield more biogas is required by the CHP, hence less biomethane can be produced (Table 2). The extent of the decrease in energy efficiency is not the same, since the utilization of the sludge has higher effect on the cases in which the hydrolysis residue is subjected to $\mathrm{AD}$, i.e. these cases are more sensitive for all the changes, which are associated with the sludge.

The most energy demanding process step is the distillation in spite of the heat integration implemented by thermally coupled columns (Table 3). It is due to the low ethanol concentration in the fermented broth, which is around $3 \%$ in all scenarios of base case A. Energy demand of the pretreatment step is also very high (Table 3), however the applied temperature is relatively low. Decreasing the energy demands of distillation and pretreatment is necessary to achieve higher energy efficiencies.

\subsection{Base case B}

In the base case $B$ the process is extended so that the biorefinery can produce an additional value-added product, that is xylitol. In these scenarios the hemicellulose fraction is separated in filterpress, and then it is subjected to xylitol fermentation. A preliminary study was also carried out in this base case, which elucidated the need for the division of hemicellulose fraction between the anaerobic digestion and the xylitol production. If the hemicellulose fraction was used exclusively for xylitol fermentation, there would not be enough steam available, which is due to both the reduced biogas production in the $\mathrm{AD}$ and the extra heat demand of the evaporation step in the xylitol production. Using $80 \%$ of the hemicellulose fraction for producing xylitol, the heat demand of the process can be covered by combusting the main part of raw biogas (cases B1 and B2, data not shown). The biogas excess is considered to be less than the amount needed for an economically-feasible gas upgrading system, thus the whole amount of raw biogas is subjected to incineration. Hence, steam excess is appeared, which operates a low-pressure turbine to make electricity.

In scenario $\mathrm{B} 1$, the feed stream of xylitol production contains $74 \mathrm{~g} / \mathrm{L}$ xylose, $38 \mathrm{~g} / \mathrm{L}$ arabinose, and $4 \mathrm{~g} / \mathrm{L}$ glucose. The achieved xylitol and cell mass concentration after the first fermentation step is $51 \mathrm{~g} / \mathrm{L}$ and $14 \mathrm{~g} / \mathrm{L}$, respectively. These concentrations are higher, than most of the data obtained in experimental works, as one of the highest xylitol yields was set in the simulation from the yields published [34]-[36], as the hemicellulose fraction, which is hydrolyzed with weak acid treatment at low temperature, does not contain any inhibitory compounds for the xylitol fermentation. After the second fermentation step the xylitol concentration increases to $78 \mathrm{~g} / \mathrm{L}$. It is presumed during this step, that the xylitol production of the genetically modified Escherichia coli is not repressed by the high xylitol concentration. The theoretical amount of the xylitol produced from the xylose and arabinose contents of the raw material is 36030 tonnes/year, however, the produced xylitol in case B1 is only 6733 tonnes/year (Table 4), which is $19 \%$ of the theoretical. It is due to the low yield of crystallization (47\%) and the xylitol loss in the filterpress steps and during the treatment with activated charcoal. The achieved yield of ethanol production is $77 \%$ of the theoretical in cases B1, B3, and B4, as annually 
Tab. 3. Energy demand of the process steps related to the energy consumption of the whole process

\begin{tabular}{|c|c|c|c|c|c|c|c|c|c|c|c|}
\hline & & \multicolumn{10}{|c|}{ Scenarios } \\
\hline & & $\mathrm{A} 1$ & A2 & A3 & A4 & A5 & A6 & A7 & A8 & A9 & A10 \\
\hline \multirow{3}{*}{ 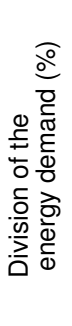 } & Pretreatment & 38 & 38 & 41 & 41 & 36 & 40 & 38 & 38 & 38 & 38 \\
\hline & Distillation & 42 & 42 & 46 & 41 & 45 & 42 & 43 & 43 & 42 & 42 \\
\hline & Other & 20 & 20 & 13 & 13 & 23 & 15 & 20 & 19 & 20 & 20 \\
\hline
\end{tabular}

Tab. 4. Process details of the scenarios investigated in base case B.

\begin{tabular}{|c|c|c|c|c|}
\hline Scenarios & B1 & B2 & B3 & B4 \\
\hline Part of hemicellulose fraction used for xylitol production & 0.8 & 0.8 & 0.5 & 0.3 \\
\hline DM content of the filterpressed solid streams (\%) & 40 & 30 & 40 & 40 \\
\hline \multicolumn{5}{|l|}{ Component flows of xylitol fermentation $(\mathrm{kg} / \mathrm{h})$} \\
\hline xylose input & 1698 & 1698 & 1061 & 637 \\
\hline arabinose input & 875 & 875 & 547 & 328 \\
\hline xylitol derived from xylose & 1155 & 1155 & 722 & 433 \\
\hline xylitol derived from arabinose & 614 & 607 & 384 & 230 \\
\hline added glycerol & 427 & 422 & 267 & 160 \\
\hline yeast cell mass (Candida strain) & 319 & 319 & 199 & 120 \\
\hline bacterial cell mass (Escherichia coli strain) & 169 & 167 & 106 & 63 \\
\hline \multicolumn{5}{|l|}{ Biogas streams $(\mathrm{kg} / \mathrm{h})$} \\
\hline methane obtained from mother liquor & 440 & 432 & 275 & 165 \\
\hline methane obtained from hemicellulose fraction & 244 & 244 & 609 & 853 \\
\hline total produced methane $i$ the $A D$ & 1197 & 1197 & 1398 & 1532 \\
\hline methane incinerated in the $\mathrm{CHP}$ & 1197 & 1197 & 754 & 554 \\
\hline Produced electricity in the CHP (TJ/year) & 209 & 202 & 156 & 139 \\
\hline Process heat demand (TJ/year) & 591 & 612 & 556 & 495 \\
\hline \multicolumn{5}{|l|}{ Products (tonne/year) } \\
\hline Ethanol & 15089 & 14885 & 15089 & 15089 \\
\hline Methane & - & - & 5599 & 8520 \\
\hline Xylitol & 6733 & 6611 & 4208 & 2525 \\
\hline
\end{tabular}

Summary of the scenarios is given in Table 1. AD: anaerobic digestion,

CHP: combined heat and power, DM: dry matter.

19587 tonnes of ethanol can be produced from the starch and cellulose inputs theoretically. $65 \%$ of the xylitol produced in the sceanarios B1, B3 and B4 is obtained from xylose, however, this ratio is higher in the case B2 (Table 4). The comparison of the cases B1 and B2 establishes the conclusion that the dry matter content of the filterpressed solid streams is of significant effect. Both the ethanol and xylitol productions are diminished by reducing the DM content of the filterpressed solid streams from $40 \%$ to $30 \%$, as in the latter case less sugar is available in the supernatant utilized for ethanol fermentation and in the liquid fraction used for fermenting xylitol.

If the part of hemicellulose fraction used for xylitol fermentation is set to 0.5 (case B3), the biorefinery can produce bioethanol, biomethane and xylitol, synergistically (Table 4).
As, larger part of the hemicellulose fraction is subjected to anaerobic digestion in case B3 than in cases B1 and B2, less xylitol is available as product. In scenario B4, $30 \%$ of the hemicellulose fraction is utilized in the xylitol fermentation and recovery step, which results in further decrease of the xylitol production, however, more biomethane is produced (Table 4). By decreasing the amount of hemicellulose subjected to xylitol production less bacterial cell mass is needed in the second step of xylitol fermentation. Thus, less glycerol is added in this step (Table 4). The methane obtained from the mother liquor is $37 \%$, $20 \%$ and $11 \%$ of the total methane produced in the AD in scenario B1, B3 and B4, respectively (Table 4). This tendency is due to both the decrease of the methane obtained from mother liquor and the increase of the total methane produced in the AD. 
The process heat demand is reduced due to the decrease of the mass flow of xylitol fermentation broth subjected to evaporation, which results in decreased heat demand of this step. The process heat demand is larger in scenario B2 than in scenario B1 (Table 4) because of the increased xylitol fermentation broth volume, which is due to the increased volume of washed hemicellulose fraction.

\section{Conclusions}

Two base cases of a biorefinery processing corn fibre were modelled with Aspen Plus flow-sheeting program. In the base case A the plant is able to produce bioethanol, biomethane and electricity. Several scenarios were simulated and compared with each other in point of energy efficiency, as this is of great importance of a process producing energy carriers. If a DM content of $40 \%$ can be achieved in the solid fraction of filterpressing, it is more favourable to combust the hydrolysis residue, than subjecting it to anaerobic digestion. When the DM content of the filterpressed solid streams is changed from $40 \%$ to $30 \%$, the overall energy efficiency is not affected considerably in the scenarios of anaerobic digestion of the hydrolysis residue, but significant change occurs in the cases of incineration of the hydrolysis residue. There is also significant influence of the aerobic sludge yield. Energy efficiency can be increased by incinerating the sludge, and by implementing district heating with the aid of flue gas condensation. The highest energy efficiency is achieved in that scenario, which contains the following settings: incineration of the hydrolysis residue and sludge, production of district heat, aerobic sludge yield of $0.5 \mathrm{~kg} \mathrm{DM} / \mathrm{kg}$ COD and DM content of the filterpressed solid streams of $40 \%$. The energy efficiency of all scenarios could be increased by decreasing the energy demands of distillation and pretreatment, as these steps have the largest energy consumption in the process.

In the base case B, the process is able to produce bioethanol, biomethane, electricity and xylitol, parallelly. The scenarios were compared in terms of mass flows of the products, as in this base case, beside the energy carriers, a food component is also produced. To produce bioethanol, biomethane and xylitol at the same time, the hemicellulose fraction has to be shared between anaerobic digestion and xylitol fermentation. By the division of hemicellulose fraction, the amounts of produced biomethane and xylitol can be varied and adjusted to the market conditions. Although it was not considered in this study, the amount of the bioethanol can also be varied by dividing the sugar-rich liquid obtained in enzymatic hydrolyses of starch and cellulose between ethanol fermentation and anaerobic digestion. Hence, by decreasing the bioethanol production more biomethane can be produced, which is also a possibility of market adaptation.

\section{References}

1 Sassner P, Galbe M, Zacchi G, Techno-Economic Aspects of a Wood-toEthanol Process: Energy Demand and Possibilities for Integration, Chemical Engineering Transactions 12 (2007), 447-452.
2 Kálmán G, Réczey K, Possible ways of bio-refining and utilizing the residual lignocelluloses of corn growing and processing, Periodica Polytechnica 51 (2007), 29-36, DOI 10.3311/pp.ch.2007-2.05.

3 Mussatto S I, Dragone G, Guimaraes P M R, Technological trends, global market, and challenges of bio-ethanol production, Biotechnology Advances 28 (2010), 817-830, DOI 10.1016/j.biotechadv.2010.07.001.

4 2012, available at http://www.biofuels-platform.ch/en/infos/ production.php?id=bioethanol

5 Galbe M, Sassner P, Wingren A, Zacchi G, Process Engineering Economics of Bioethanol Production, Biofuels Book Series: Advances in Biochemical Engineering-Biotechnology, 2007, pp. 303-327, DOI 10.1007/10_2007_063.

6 Chen H, Qiu W, Key technologies for bioethanol production from lignocellulose, Biotechnology Advances 28 (2010), 556-562, DOI 10.1016/j.biotechadv.2010.05.005.

7 Barta Zs, Kovacs K, Réczey K, Zacchi G, Process Design and Economics of On-Site Cellulase Production on Various Carbon Sources in a Softwood-Based Ethanol Plant, Enzyme Research, posted on 2010, DOI 10.4061/2010/734182, (to appear in print). 734182.

8 Cardona C A, Sanchez 0 J, Fuel ethanol production: Process design trends and integration opportunities, Bioresource Technology 98 (2007), 2415-2457, DOI 10.1016/j.biortech.2007.01.002.

9 Taylor G, Biofuels and the biorefinery concept, Energy Policy 36 (2008), 4406-4409, DOI 10.1016/j.enpol.2008.09.069.

10 Smith W, Literature Review: State of the Art in Biorefinery Development, 2007. (NFC 07/008).

11 Carvalheiro F, Duarte L C, Girio F M, Hemicellulose biorefineries: a review on biomass pretreatments, Journal of Scientific \& Industrial Research 67 (2008), 849-864.

12 Sassner P, Zacchi G, Integration options for high energy efficiency and improved economics in a wood-to-ethanol process, Biotechnology for Biofuels 1/4 (2008), DOI 10.1186/1754-6834-1-4.

13 Barta Zs, Réczey K, Zacchi G, Techno-economic evaluation of stillage treatment with anaerobic digestion in a softwood-to-ethanol process, Biotechnology for Biofuels 3 (2010), no. 21, DOI 10.1186/1754-6834-3-21.

14 Kálmán G, Recseg K, Gáspár M, Réczey K, Novel approach of corn fiber utilization, Applied Biochemistry and Biotechnology 131 (2006), 738-750, DOI 10.1385/ABAB:131:1:738.

15 Gáspár M, Juhász T, Szengyel Z, Fractionation and utilisation of corn fibre carbohydrates, Process Biochemistry 40 (2005), 1183-1188, DOI 10.1016/j.procbio.2004.04.004.

16 Rose D J, Inglett G E, Liu S X, Utilisation of corn (Zea mays) bran and corn fiber in the production of food components, Journal of the Science of Food and Agriculture 90 (2010), 915-924, DOI 10.1002/jsfa.3915.

17 Leathers TD, Bioconversions of maize residues to value-added coproducts using yeast-like fungi, Fems Yeast Research 3 (2003), 133-140, DOI 10.1016/S1567-1356(03)00003-5.

18 Gáspár M, Kálmán G, Réczey K, Corn fiber as a raw material for hemicellulose and ethanol production, Process Biochemistry 42 (2007), 1135-1139, DOI 10.1016/j.procbio.2007.04.003.

19 Nghiem N P, Montanti J, Johnston D B, Fractionation of Corn Fiber Treated by Soaking in Aqueous Ammonia (SAA) for Isolation of Hemicellulose B and Production of C5 Sugars by Enzyme Hydrolysis, Applied Biochemistry and Biotechnology 164 (2011), 1390-1404, DOI 10.1007/s12010-011-9220-4.

20 Chen K, Jiang M, Wei P, Succinic Acid Production from Acid Hydrolysate of Corn Fiber by Actinobacillus succinogenes, Applied Biochemistry and Biotechnology 160 (2010), 477-485, DOI 10.1007/s12010-008-8367-0.

21 Wooley R J, Putsche V, Development of an Apen Plus Physical Property Database for Biofuels Components, 1996. NICH Report TP-425-20685.

22 Wingren A, Galbe M, Zacchi G, Techno-economic evaluation of produc- 
ing ethanol from softwood: Comparison of SSF and SHF and identification of bottlenecks, Biotechnology Progress 19 (2003), 1109-1117, DOI 10.1021/bp0340180.

23 Grahs L E, Displacement Washing of Packed-Beds of Cellulose Fibers, Part 1. A Comparison of the Behaviour of Sodium and Lignin, Svensk Papperstidning-Nordisk Cellulosa 79 (1976), 123-128.

24 Destexhe A, Peckous L, Picart L, Using enzymes in ethanol production, 2004. Novozymes A/S.

25 Erdei B, Barta Zs, Sipos B, Ethanol production from mixtures of wheat straw and wheat meal, Biotechnology for Biofuels 3 (2010), no. 16, DOI 10.1186/1754-6834-3-16

26 Sassner P, Galbe M, Zacchi G, Techno-economic evaluation of bioethanol production from three different lignocellulosic materials, Biomass \& Bioenergy 32 (2007), 422-430, DOI 10.1016/j.biombioe.2007.10.014.

27 Ljunggren M, Zacchi G, Techno-economic analysis of a two-step biological process producing hydrogen and methane, Bioresource Technology 101 (2010), 7780-7788, DOI 10.1016/j.biortech.2010.05.009.

28 Ljunggren M, Zacchi G, Techno-Economic Evaluation of a Two-Step Biological Process for Hydrogen Production, Biotechnology Progress 26 (2010), 496-504, DOI 10.1002/btpr.336.

29 Wei Y S, Van Houten R T, Borger A R, Minimization of excess sludge production for biological wastewater treatment, Water Research 37 (2003), 4453-4467, DOI 10.1016/S0043-1354(03)00441-X.

30 Walther T, Hensirisak P, Agblevor F A, The influence of aeration and hemicellulosic sugars on xylitol production by Candida tropicalis, Bioresource Technology 76 (2001), 213-220, DOI 10.1016/S09608524(00)00113-9.

31 Sakakibara Y, Saha B C, Taylor P, Microbial production of xylitol from L-arabinose by metabolically engineered Escherichia coli, Journal of Bioscience and Bioengineering 107 (2009), 506-511, DOI 10.1016/j.jbiosc.2008.12.017.

32 Misra S, Gupta P, Raghuwanshi S, Comparative study on different strategies involved for xylitol purification from culture media fermented by Candida tropicalis, Separation and Purification Technology 78 (2011), 266-273, DOI 10.1016/j.seppur.2011.02.018.

33 Yuan Z G, Blackall L L, Sludge population optimisation: a new dimension for the control of biological wastewater treatment systems, Water Research 36 (2002), 482-490, DOI 10.1016/S0043-1354(01)00230-5.

34 Rao R S, Jyothi Ch. P, Prakasham R S, Xylitol production from corn fiber and sugarcane bagasse hydrolysates by Candida tropicalis, Bioresource Technology 97 (2006), 1974-1978, DOI 10.1016/j.biortech.2005.08.015.

35 Leathers TD, Dien BS, Xylitol production from corn fibre hydrolysates by a two-stage fermentation process, Process Biochemistry 35 (2000), 765-769, DOI 10.1016/S0032-9592(99)00137-5.

36 Buhner J, Agblevor FA, Effect of detoxification of dilute-acid corn fiber hydrolysate on xylitol production, Applied Biochemistry and Biotechnology 119 (2004), 13-30, DOI 10.1385/ABAB:119:1:13. 